\title{
INVESTIGATION ON THE BLAST RESISTANCE OF A STIFFENED DOOR STRUCTURE
}

\author{
Ming-Wei Hsieh \\ Department of Mechanical Engineering, Nanya Institute of Technology, Taoyuan County, Taiwan, R.O.C. \\ Jui-Pin Hung \\ Department of Mechanical Engineering, National Chin-Yi University of Technology, Taichung County, Taiwan, R.O.C., \\ hungjp@ncut.edu.tw \\ De-Jen Chen \\ Department of Mechanical Engineering, Nanya Institute of Technology, Taoyuan County, Taiwan, R.O.C.
}

Follow this and additional works at: https://jmstt.ntou.edu.tw/journal

Part of the Mechanical Engineering Commons

\section{Recommended Citation}

Hsieh, Ming-Wei; Hung, Jui-Pin; and Chen, De-Jen (2008) "INVESTIGATION ON THE BLAST RESISTANCE OF A STIFFENED DOOR STRUCTURE," Journal of Marine Science and Technology: Vol. 16: Iss. 2, Article 7.

DOI: $10.51400 / 2709-6998.2025$

Available at: https://jmstt.ntou.edu.tw/journal/vol16/iss2/7

This Research Article is brought to you for free and open access by Journal of Marine Science and Technology. It has been accepted for inclusion in Journal of Marine Science and Technology by an authorized editor of Journal of Marine Science and Technology. 


\section{INVESTIGATION ON THE BLAST RESISTANCE OF A STIFFENED DOOR}

STRUCTURE

\section{Acknowledgements}

The authors are grateful for the financial support provided by the National Science Council of Taiwan under the grant of NSC92-2622-E-253-005-CC3. The assistances from Wei-Jie Engineering Co., Ltd and Song-Yang Machinery Industrial Co., Ltd, respectively, for preparation of the test specimen and implementation of experiments, are also greatly appreciated. 


\title{
INVESTIGATION ON THE BLAST RESISTANCE OF A STIFFENED DOOR STRUCTURE
}

\author{
Ming-Wei Hsieh*, Jui-Pin Hung**, and De-Jen Chen*
}

Key words: blast resistance, stiffened door structure, transient analysis.

\begin{abstract}
This study was aimed at investigating the blast resistance of a stiffened door structure. For this, a series of finite element transient analysis were performed to predict the dynamic response of blast resistant doors. Current results show that the stiffeners have sustained the majority of the explosive loadings. The effect of stiffener size on the stress state was rated in terms of the ratio of stiffener stress to plate stress, which was enhanced with the increase of web thickness of stiffener. Additional, the highest stresses were shown to occur at the transverse stiffeners near the hinged sides with a maximum stress above the dynamic yield strength, indicating the local yielding at these points. However, the rotational deformations of hinged support were within the deformation limit required for medium level of protection. In final, a static compressive experiment was carried out on prototype door structure to measure the static stiffness according to the test criteria given in TM5-1300. The numerically predicted results were demonstrated to agree well with the experimental results, showing a good performance of the door structure against blast loads was achieved.
\end{abstract}

\section{INTRODUCTION}

In recent years unexpected explosions threatening the public security are increasing owing to the prevailing of the terrorism. The demand for commercial building or military structures with blast-resistant design is therefore urgent than ever before. Generally, the commercial or military constructions can be strengthened by using reinforced concrete walls. However, the entrances can not be completely sealed off under consideration of free pass. Thus, a variety of blast resistant door with sufficient explosion capacity were designed for various applications.

Paper submitted 02/02/07; accepted 06/04/07 Author for correspondence: Jui-Pin Hung (e-mail:hungjp@ncut.edu.tw).

*Department of Mechanical Engineering, Nanya Institute of Technology, Taoyuan County, Taiwan, R.O.C.

**Department of Mechanical Engineering, National Chin-Yi University of Technology, Taichung County, Taiwan, R.O.C.
Such a blast-resistant door could be constructed as stiffened steel plate, reinforced concrete structure or sandwich structure.

For the design work of blast resistance structure, it is well recognized that two important technologies, including structural dynamic analysis and blast aerodynamics, are involved. Especially, the dynamic response to explosive loading should be taken into consideration during design stage. On other respect, the identification of the explosive loading characteristics such as peak pressure and loading duration of blast wave is a prerequisite prior to mechanical analysis. Although studies on blast loading model can be available in literatures, quantification of the blast parameters has been a highly complicated task with professional techniques. Accordingly, most of the blast door structures were designed under the guidelines provided in the military technical manual TM5-1300 [2], NAVFAC P-397 [3], and the analysis work was performed following the official design criteria. Essentially, the structural stiffness of blast door was estimated under different blast loads and then the blast resistance was evaluated according to the material strength, making sure whether the structure could meet the requirement in explosion capacity. As to the dynamic analysis presented in TM5-1300, a simplified single-degree-of-freedom system was usually employed to simulate the dynamic responses of the whole structure under the blast shock wave, by which the maximum distortion, time-history of acceleration can then be investigated. In this analytical approach, the load-mass factor and blast pressure-time relationship used for the calculation of the equivalent weight of structure can be available from literatures [2, 3].

Regarding the failure analysis of blast resistance structure, most researches had paid attention on investigating the performance of stiffened or unstiffened metal plates of small scale, rather than the door structure of large scale. For example, Nurick et al. [12,13] and Rudrapatna et al. [14], respectively, reported the possible failure modes of a stiffened plate under explosive pressure by means of numerical and experimental investigation. Their works indicated that the plate structure might fail in different modes depending on the loading conditions applied on the plate, while the stiffener size was proven to have no profound effect on the failure modes. Louca et al. [8] also presented comparison investigations on the dynamic response of stiffened and unstiffened plates by numerical method. The results showed that the effect of the boundary conditions on 
the dynamic response was significant. Zhu [16] predicted the transient deformation of unstiffened square plates made of various materials under explosive loadings and compared the numerical results with experimental investigation based on optical techniques. However, in commercial application for civilian building, a large scale door structure should have sufficient capacity to resist the blast loads in actual situation.

To this purpose, a door structure of general-duty type was designed with two surface plates and multiple inter-stiffeners along vertical and transverse span, in which the I-shaped stiffeners can sustain and disperse the explosive loading impacted on surface plate, being expected to increase the required anti-blast capacity. As reported in literatures [12-14], the stiffened steel plate has been showed to have good performance than unstiffened plates although the stiffened girders welded to the surface plates may suffer from the destructions of the tensile or tearing failure at the edge side. Recently, Langdon et al. [7] further demonstrated that the stiffener configuration had more effect on the response of the locally-loaded plates. It is therefore of importance to investigate the influence of the stiffener size on the mechanical behavior of a door structure strengthened with multiple stiffeners, while such an effect was not fully discussed in TM5-1300 [2] or other researches.

For a long time, the technology development of blast-resistant structure was aimed at military facilities and could not be accessed for general application in industry. Recently, with the advancement in computer technology, lots of analysis software packages have been developed by implementing the theoretical mechanics into finite element method, which can provide an efficient tool in analyzing the dynamic behavior of complicated structures. This study was therefore aimed to investigate the blast resistance of a door structure with multiple inter-stiffeners by using finite element analysis and static stiffness experiment. This approach can be used for simulating the effect of structural modification on the anti-blast capability and was expected to help the structural engineerer to design other blast-resistant facilities for different applications.

\section{CHARACTERISTICS OF BLAST WAVE}

In the design of blast door, the structural dynamic behavior responding to explosive loads should be investigated in detail. While the blast effects are described as the shock wave of high-pressure shock front impinging on the target and then decaying with time. Prior to analysis, it is therefore necessary to establish the properties of a blast wave such as peak overpressure, reflected peak pressure and loading duration. These properties are highly dependent on the explosive charge weight, detonation distance to target, geographical surrounding and atmospheric pressure. The details of the blast characteristics for a variety of explosives can be enquired from empirical charts or formulae in military technical manual TM5-1300 [2], blast effect analysis software [15] or statistical analysis [1,10,11] during design procedure. As an example in theorem [6], the peak overpressure $P_{s}$ and duration of positive pressure $t_{s}$ can be

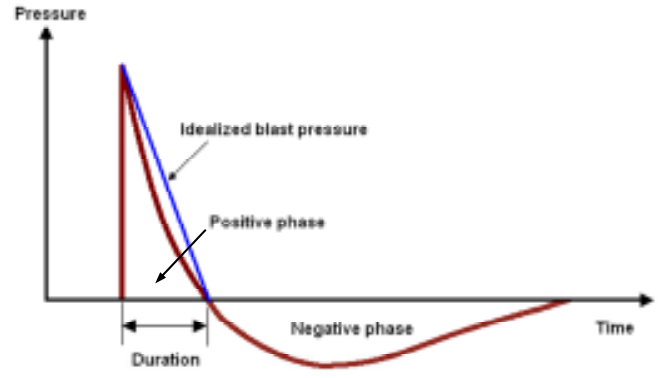

Fig. 1. Time history of a typical blast wave pressure and idealized triangular wave.

expressed as the function of the scaled distance $Z$ and explosive charge weight $W$, respectively. That is,

$$
\begin{gathered}
\frac{P_{S}}{P_{0}}=\frac{808\left[1+\left(\frac{Z}{4.5}\right)^{2}\right]}{\sqrt{1+\left(\frac{Z}{0.048}\right)^{2}} \cdot \sqrt{1+\left(\frac{Z}{0.32}\right)^{2}} \cdot \sqrt{1+\left(\frac{Z}{1.35}\right)^{2}}} \\
\frac{t_{S}}{W^{1 / 3}}=\frac{980\left[1+\left(\frac{Z}{0.54}\right)^{10}\right]}{\left[1+\left(\frac{Z}{0.002}\right)^{3}\right] \cdot\left[1+\left(\frac{Z}{0.74}\right)^{6}\right] \cdot \sqrt{1+\left(\frac{Z}{6.9}\right)^{2}}}
\end{gathered}
$$

where $P_{0}$ is the atmospheric pressure (bar) and the scaled distance parameter $Z$ is a measure to compare the blast effect generated from different explosions, which is attributed to Hopkinson [4] and is given by the form $Z=R / W^{1 / 3}$ ( $R$ and $W$ are the stand-off distance from detonation to the target, in $\mathrm{ft}$ and equivalent TNT charge weight, in Lb). The peak reflected pressure $P_{\text {rmax }}$ can be obtained from the following equation [10].

$$
P_{r \max }=\frac{2 P_{\max }\left(710+4 P_{\max }\right)}{710+P_{\max }}
$$

Here $P_{\max }$ is the peak overpressure of the shock wave.

Besides, a definition describing the variation of the blast pressure as a function of time is required for dynamic analysis. For this, many mathematical models were developed, in which the simplified single impulse-duration relation of triangular shape was mostly used to simulate the experimentally obtained pressure-time history [5] (see Fig. 1), that is,

$$
P(t)=P_{\max }\left(1-\frac{t}{t_{0}}\right)
$$

in which $t_{0}$ is the duration of the blast wave for triangular loading representation, $P_{\max }$ represents the peak pressure of the shock wave in positive phase or negative phase. 


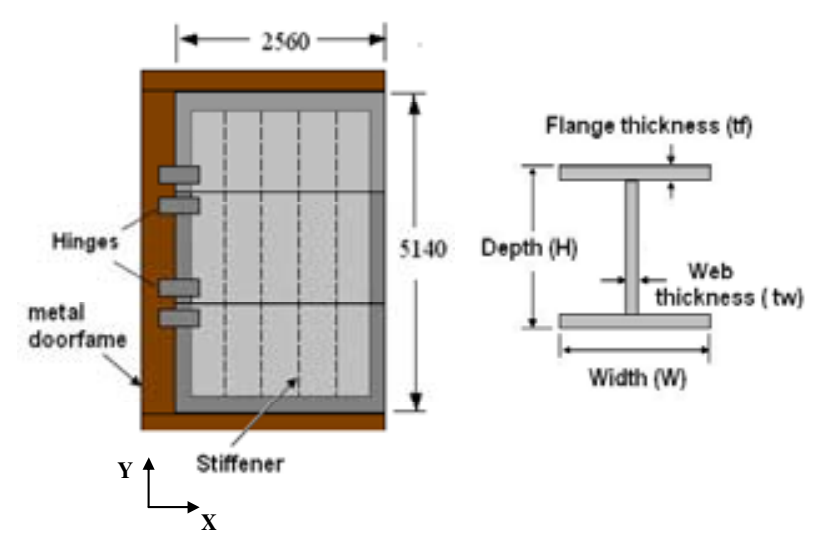

Fig. 2. Schematic of the blast door and specification of the I-shaped inter-stiffener. The size of rectangular plate is $5140 \mathrm{~mm} \times$ $2560 \mathrm{~mm}$ and $20 \mathrm{~mm}$ of thickness. The stiffener has dimensions as follows: width $(W)=120 \mathrm{~mm}$, thickness ratio $\left(t_{f} / t_{w}\right)=1.10$, and the $\operatorname{depth}(\mathrm{H})$ and web thickness $t_{w}$ being determined in this study.

\section{FINITE ELEMENT ANALYSIS}

\section{Basic Specifications of Blast Door}

Blast resistant doors are normally designed with enough load carrying capacity to resist a high pressure shock front of very short duration. The main structure of blast door of a general-duty type was usually constructed utilizing two high-tension steel plates with inner space. The inner space is designed with various interior structures, such as reinforced concrete or masonry, structural steel ribbing or girders. The door structure employed in this study was strengthened with inter-stiffeners of the I-shaped beam along vertical and transverse spans. Fig. 2 depicted the geometrical configuration of the whole structure and the detailed specification of the I-shaped beam. Fig. 3 is the solid model of the blast door created for analysis. Such a design can be constructed into a paired door leafs or single door leaf in future application. The essential dimensions of the blast door used in this study are $2560 \mathrm{~mm}$ in width and $5140 \mathrm{~mm}$ in height, in which the cover plate has a thickness of $20 \mathrm{~mm}$. For I-shaped inter-stiffener the width $W$ is $120 \mathrm{~mm}$ and the ratio of flange thickness $t_{f}$ to web thickness $t_{w}$ is 1.10. Other dimensions such as the web thickness $t_{w}$ and depth $H$ are determined from subsequent analysis.

As stated in previous, the geometry specification of blast door is mainly designed according to the rated blast capacity and protection level specified for application. The blast pressure can be generated by different explosive mass detonated at various stand-off distances. As listed in Table 1, the properties of shock wave with different combinations of stand-off distance and TNT explosive mass are summarized. In this study, the desired blast-resistant capacity is rated at 3 bars $(0.3 \mathrm{MPa})$ for positive peak overpressure and 6 bars $(0.6 \mathrm{MPa})$ for peak reflected pressure. Such a simulated blast pressure can be approximately generated by an explosion of $362 \mathrm{Kg}$ (800Lb) of TNT detonated at a standoff distance of $12.2 \mathrm{~m}$ (40ft).

On the other hand, a qualified door structure should provide a

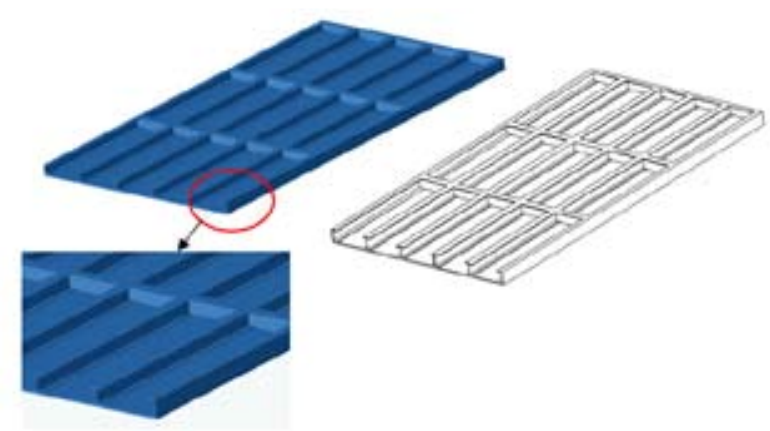

Fig. 3. Solid model of the blast door structure, including metal skin plate and inter-stiffener.

Table 1. Characteristics of blast wave with different $W$-R combinations.

\begin{tabular}{cccccc}
\hline $\begin{array}{c}\text { TNT explo- } \\
\text { sive charge, } \\
\mathrm{Lb}(\mathrm{Kg})\end{array}$ & $\begin{array}{c}\text { Stand-off } \\
\text { distance, } \\
\mathrm{ft}(\mathrm{m})\end{array}$ & $\begin{array}{c}\text { Scaled } \\
\text { distance }\end{array}$ & $\begin{array}{c}\text { Peak } \\
\text { overpressure, } \\
(\mathrm{Bar})\end{array}$ & $\begin{array}{c}\text { Positive } \\
\text { duration } \\
(\mathrm{ms})\end{array}$ & $\begin{array}{c}\text { Reflective } \\
\text { blast pres- } \\
\text { sure }\end{array}$ \\
\hline $500(227)$ & $40(12.1)$ & 1.99 & 2.05 & 7.13 & 6.89 \\
$600(272)$ & $40(12.1)$ & 1.88 & 2.36 & 7.15 & 8.31 \\
$800(362)$ & $40(12.1)$ & 1.70 & 2.95 & 7.17 & 11.18 \\
$1000(453)$ & $40(12.1)$ & 1.58 & 3.51 & 7.18 & 14.08 \\
$500(227)$ & $30(9.1)$ & 1.49 & 4.01 & 5.37 & 16.77 \\
$600(272)$ & $30(9.1)$ & 1.41 & 4.61 & 5.35 & 20.20 \\
$800(362)$ & $30(9.1)$ & 1.28 & 5.73 & 5.29 & 26.97 \\
$1000(362)$ & $30(9.1)$ & 1.19 & 6.78 & 5.20 & 33.59 \\
\hline
\end{tabular}

least damage to its occupants and contents, and the damage extent is restricted by the protection level prescribed in TM5-1300. In this study, the door structure is expected to provide a medium level of protection, which means the door leaf is allowed to deform with a rotational deformation of 2 degree at supports and can be repairable after explosions. For one way door leaf, the maximum support rotations deformation $\theta_{\max }$ is related to the maximum deflection $\delta_{\max }$ and the door width $W$ by the equation of the form $\operatorname{Tan}\left(\theta_{\max }\right)=2 \delta_{\max } / W$. Besides, the material of the door plate is ASTM A515 grade 50 with following properties: Young's modulus E=209 GPa, Poisson's ratio $v=0.30$, density $\rho=7830 \mathrm{~kg} / \mathrm{m}^{3}$, static yield strength $\sigma_{\text {yield }}=265 \mathrm{MPa}$, ultimate tensile strength $\sigma_{u t}=492 \mathrm{MPa}$. The stiffener is made of ASTM A-36 steel, with static yield strength of $248 \mathrm{MPa}$ and tensile strength of $400 \mathrm{MPa}$. In addition, for the simulated blast pressure, the duration of impulsive load is approximately $7 \mathrm{~ms}$, causing a loading rate of $140 \mathrm{~s}^{-1}$ more. Therefore, the enhancement of material strength can be expected due to the blast effect and the dynamic strength can be obtained from static strength by multiplying a dynamic increase factor [9]. As suggested in the design chart of TM5-1300, the dynamic increase factor were 1.29 for AISI A36 steel and 1.09 for AISI A515 steel, giving the dynamic yield strength of $320 \mathrm{MPa}$ for stiffener and $289 \mathrm{MPa}$ for plate, respectively. 

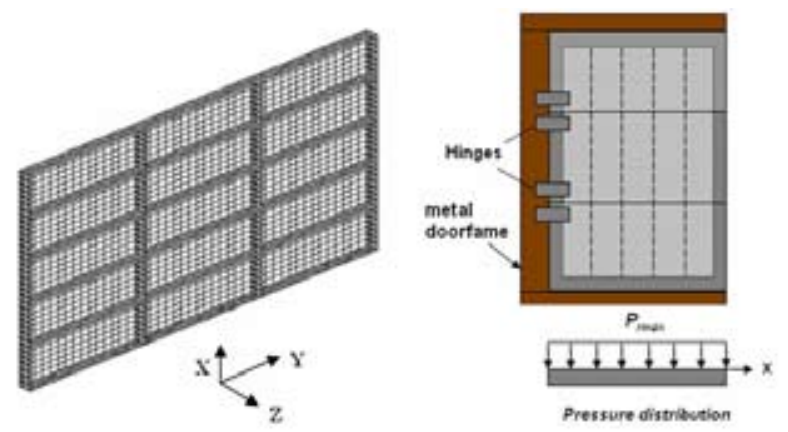

Fig. 4. Finite element model of a blast door structure with inter-stiffener modeled with shell element. A uniform distributed blast pressure was applied on the cover plate.

\section{Finite Element Modeling}

For numerical analysis, a finite element model of the blast door structure was created and depicted in Fig. 4. Due to high aspect ratio in width/thickness of the metal plate, the outer skin metal plates were simulated with shell element. For I-shaped inter-stiffener the central wedge was simulated with beam element and the upper/bottom flanges were modeled using shell element. Since the blast door considered in this study was a double swinging door, only a single door leaf was modeled to reflect symmetry in geometry. The left side of the door plate was clamped on the metal doorframe using two heavy-duty hinges (Fig. 4). The right side was assumed to be free because it was locked by one point latch. While the upper and bottom edges of the inside cover plate were fully constrained by the metal doorframe when it is in close state. In finite element analysis, the material characteristics of the plate and stiffener were presented as linear elastic material model.

To accurately predict the stress state of door structure under explosive loading, different mesh density was adopted to create the analysis model for convergence test. The numbers of element/node were 3180/2942, 5610/5292 and 9360/8952, respectively. By carrying out modal analysis on the three models, the natural frequencies of the first five vibration modes for each meshed model were taken for comparisons (Table 2). It was found from Table 2 that the maximum deviation in frequency obtained from model 2 and model 3 was $0.058 \%$, showing the convergent solution was achieved. Considering the efficiency in numerical computation, the finite element model for different stiffener sizes were therefore constructed based on the model 2 .

\section{Static Analysis}

The static analysis was first performed to investigate the effect of stiffener size on the stiffness and stress state of the whole structure under explosive loading of static mode. Since a reflected peak pressure of $0.6 \mathrm{MPa}$ was expected to produce a more rigorous stress within the door structure and hence the blast pressure was applied over the exterior surface of cover plate as a uniform distributed load, as shown in Fig. 4. The depth of stiffener was assumed to be 140,150 and $160 \mathrm{~mm}$, respectively and the thickness of web was 5.5, 6.5, 7.5 and 8.5 $\mathrm{mm}$, respectively. Basing on this analysis, we could present appropriate stiffener size for subsequent dynamic analysis.
Table 2. Natural frequencies of the first five modes of door structure.

\begin{tabular}{cccc}
\hline \multirow{2}{*}{$\begin{array}{c}\text { Vibra- } \\
\text { tion mode }\end{array}$} & \multicolumn{3}{c}{ Frequency of natural vibration (Hz) } \\
\cline { 2 - 4 } & Model-1 & Model-2 & Model-3 \\
\hline 1 & 53.249 & 53.009 & 52.986 \\
2 & 95.501 & 95.171 & 95.170 \\
3 & 105.05 & 104.99 & 104.99 \\
4 & 136.25 & 136.18 & 136.26 \\
5 & 154.537 & 154.66 & 154.79 \\
\hline
\end{tabular}

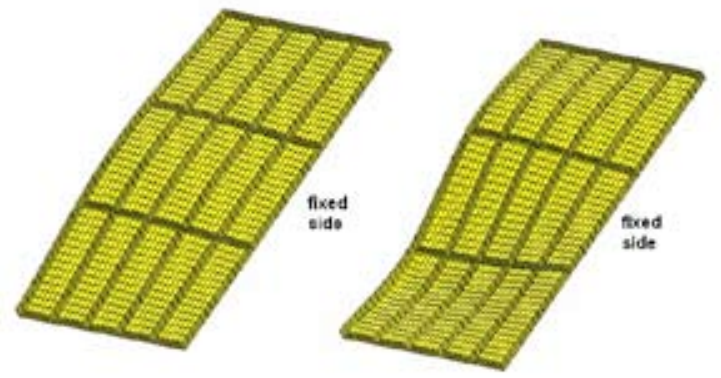

Fig. 5. Fundamental vibration modes of the door structure, belonging to bending vibration.

\section{Transient Analysis}

The result of modal analysis reveals that the door structure has the first bending vibration mode, as shown in Fig. 5. The door structure can be excited to vibrate at bending mode when the blast wave suddenly impinges on the skin plate after detonation. Therefore, the stress state generated by impulsive force should be taken into consideration in design stage.

Generally, equations that govern the dynamic response of the blast resistant structure subjected to explosive loading can be derived from D'Alembert principle and written into the finite element formulation.

$$
[M]\{\ddot{d}\}+[C]\{\dot{d}\}+[K]\{d\}=\left\{F^{e x t}\right\}
$$

where $[M],[C]$ and $[K]$ are the mass matrix, damping matrix and stiffness matrix of the whole structure, respectively. $\{d\},\{\dot{d}\}$ and $\{\ddot{d}\}$ are the system nodal displacement, velocity and acceleration, respectively. $\left\{F^{e x t}\right\}$ is the applied force vector. Since the duration of explosive loading is very short, the blast pressure acting on the door structure can be referred to as an impulse. For mechanical components subject to the impulsive excitation, the effect of stress wave propagating within the material is of great importance in analysis. The stress wave will cause the stress distribution in mechanical components to vary with time and bring the stress to higher levels than that predicted under static loadings. For the solution of (5), the direct integration by the trapezoidal rule method is implemented in the finite element algorithm and the time-history of the displacement and stress fields can be obtained. 


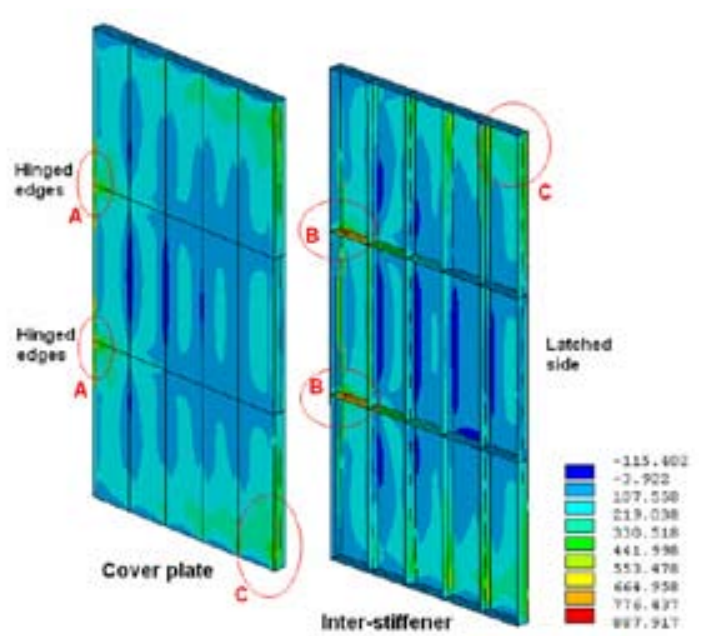

Fig. 6. Representative distributions of maximum principal stress of door structure under static explosive loading mode, showing the main stress concentration areas: (A) cover plate clamped on doorframe with hinges, (B) hinged edges of transverse stiffener (C) corners supported on frame. (Stress unit: MPa)

Table 3. Comparison of the maximum stress and deflection for door structure with different stiffener sizes. (Predicted under static loading conditions)

\begin{tabular}{|c|c|c|c|c|c|c|c|}
\hline \multirow{3}{*}{$\begin{array}{c}H \\
(\mathrm{~mm})\end{array}$} & \multirow{3}{*}{$\begin{array}{c}t_{w} \\
(\mathrm{~mm})\end{array}$} & \multirow{3}{*}{$\begin{array}{c}\text { Max. } \\
\text { deflection } \\
(\mathrm{mm})\end{array}$} & \multirow{3}{*}{$\begin{array}{c}\text { Rotational } \\
\text { deformation } \\
\text { of hinged } \\
\text { support } \\
\text { (degree) }\end{array}$} & \multicolumn{4}{|c|}{ Maximum principal stress (MPa) } \\
\hline & & & & \multicolumn{2}{|c|}{$\begin{array}{l}\text { at highly stressed } \\
\text { regions, } \\
\text { corner or hinges } \\
\end{array}$} & \multicolumn{2}{|c|}{$\begin{array}{l}\text { at center portion } \\
\text { of mild stress }\end{array}$} \\
\hline & & & & $\begin{array}{l}\text { door } \\
\text { plate }\end{array}$ & stiffener & $\begin{array}{l}\text { door } \\
\text { plate }\end{array}$ & stiffener \\
\hline \multirow[t]{4}{*}{140} & 5.5 & 36.09 & 1.62 & 507 & 1076 & 183 & 661 \\
\hline & 6.5 & 34.08 & 1.52 & 499 & 984 & 175 & 574 \\
\hline & 7.5 & 32.55 & 1.46 & 492 & 823 & 170 & 483 \\
\hline & 8.5 & 31.33 & 1.40 & 485 & 737 & 158 & 456 \\
\hline \multirow[t]{4}{*}{150} & 5.5 & 32.46 & 1.45 & 482 & 968 & 182 & 564 \\
\hline & 6.5 & 30.59 & 1.37 & 473 & 842 & 174 & 502 \\
\hline & 7.5 & 29.17 & 1.30 & 464 & 742 & 166 & 450 \\
\hline & 8.5 & 28.03 & 1.25 & 457 & 664 & 158 & 406 \\
\hline \multirow[t]{4}{*}{160} & 5.5 & 29.24 & 1.31 & 456 & 893 & 181 & 551 \\
\hline & 6.5 & 27.53 & 1.23 & 446 & 774 & 174 & 481 \\
\hline & 7.5 & 26.22 & 1.17 & 439 & 684 & 166 & 437 \\
\hline & 8.5 & 25.16 & 1.12 & 432 & 613 & 158 & 386 \\
\hline
\end{tabular}

\section{RESULTS AND DISCUSSIONS}

\section{Static Analysis}

Shown in Fig. 6 is a representative distribution of the principal stress within door structure predicted under static blast loading mode. It can be seen from this figure that the highest stress is concentrated locally at particular regions, including the upper and bottom corners or tips of the plate supported by rigid frame and the stiffener edges near the hinged sides; while the remaining areas, around middle of the plate and stiffener, are at

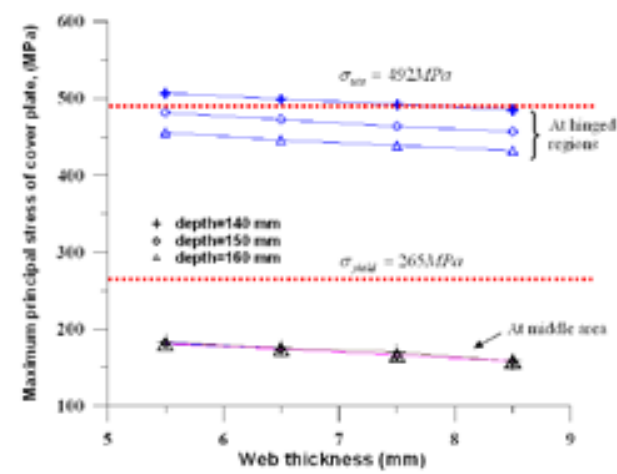

Fig. 7. Variation of maximum principal stress of cover plate with stiffener size, predicted under static explosive loading mode.

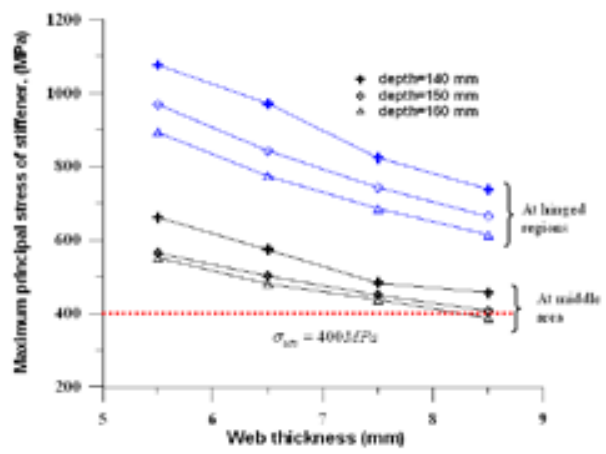

Fig. 8. Variation of maximum principal stress of stiffener with stiffener size, predicted under static explosive loading mode.

lower stress state. The stress contour plot clearly indicates that the stiffeners effectively sustain the blast pressure. Table 3 summarizes the peak stress, maximum deflection and rotational deformation at hinged support for door structures with different stiffener sizes, in which the rotational deformations are employed to evaluate the extent of damage of structure according to the protection level defined in TM5-1300. It is noted from Table 3 that the maximum tensile stresses generated at critical regions are in the range of 432 507 MPa for cover plate and 613 1076MPa for stiffener, respectively. The effect of stiffener size on the rigidity and stress of door structure can further be investigated from Figs. 7-9. It is obvious that increasing the stiffener depth and web thickness can remarkably increase the rigidity of door structure and reduce the stress generated in stiffeners. This effect can be ascribed to the fact that an I-shaped stiffener with large size has a larger inertia moment, yielding higher flexural stiffness to resist the blast loads. However, the overall stress of cover plates affected to a little by the stiffener size, except at the boundaries supported by rigid frame.

In addition, the predicted peak stresses for stiffeners are apparently higher than the yielding strength and ultimate tensile strength of the materials. Also, the stress induced on the central region of the cover plate is lower than its strength, indicating the initiation of local yielding at these locations, rather than the whole structure. On the other hand, the rotational deformations of the hinged support caused by the deflection of latched side 


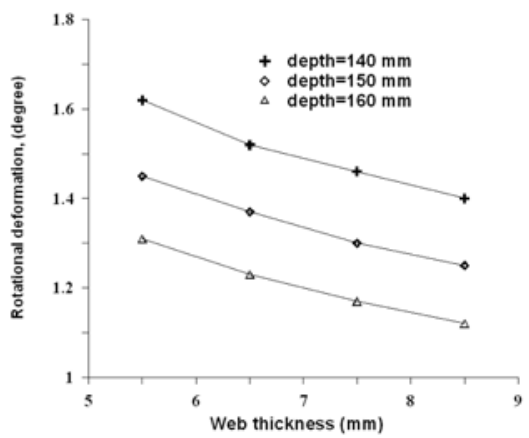

Fig. 9. Variation of rotational deformation of hinged support with stiffener size, predicted under static explosive loading mode.

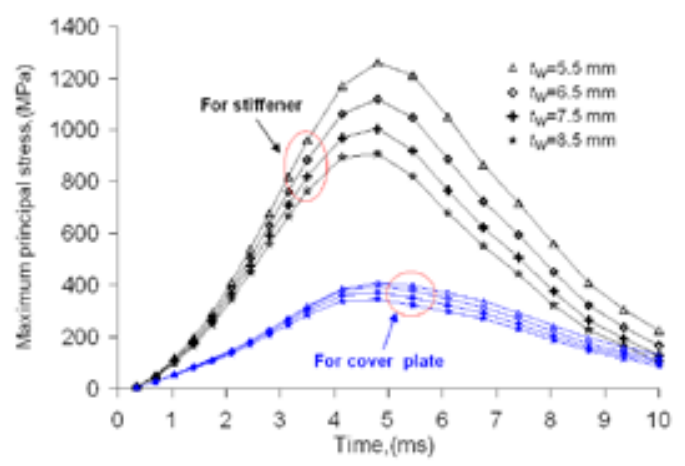

Fig. 10. Predicted time history of maximum principal stress occurred at critical points of door structure under dynamic explosive loading, stiffener being subjected to higher stress than cover plate. (Stiffener depth $\mathbf{H}=\mathbf{1 5 0} \mathrm{mm}$ ).

are far less than the deformation limit ( 2 degree) as specified in TM5-1300. This implies that the stiffener would be a major component absorbing the blast loads, hence reducing the damage to cover plate.

Concluding from the results of static analysis, it is known that the blast doors seem to be qualified with a valid protection level. However, to avoid substantial failure at critical regions, the door structure should be strengthened with adequate stiffener size or configuration. Compared to the others, the stiffener size of 150 $\mathrm{mm}$ in depth with medium stress was presented for further investigation on dynamic response.

\section{Transient Analysis}

The door structure employed in transient analysis has a depth of $150 \mathrm{~mm}$ and web thickness of $55,6.5,7.5$ and $8.5 \mathrm{~mm}$, respectively. The blast pressure applied on the door surface was $0.6 \mathrm{MPa}$, same as in static analysis, and the duration of loading was $7.0 \mathrm{~ms}$. In addition, the transient analysis was carried out under linear elastic mode since the post yielding behavior was not accounted in analysis. The time history of principal stress and deformation of the stiffened door structure after the impact of shock wave are shown in Figs. 10 and 11, respectively. For a stiffened door structure with different web thickness, there is a less difference in time to peak stress, but great deviation in the stress level. The maximum impact stresses generated in plate are

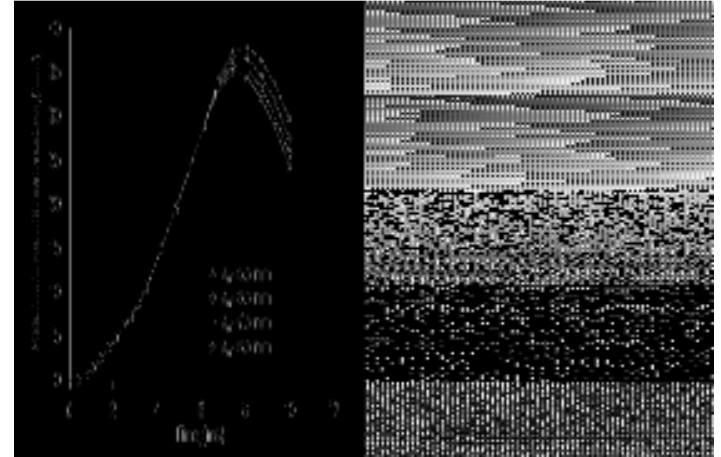

Fig. 11. Predicted time history of deformation at latched side of door structure under dynamic explosive loading. (Stiffener depth $\mathrm{H}=150 \mathrm{~mm}$ ).

far lower than those in stiffener. As a comparison, Table 4 summarizes the principal stress and deflection of the door structure predicted under different loading modes. It is found that the impact stress induced in stiffener near the hinged region is approximately $33 \%$ higher than these predicted under static loading mode. This demonstrates that the dynamic response of the structure to the blast pressure was enhanced due to the inertia effect in loading duration, while this effect was not considered in static analysis. Owing to the impact effect, the blast door was deformed seriously compared to the case of static loadings mode. However, the rotational deformations at the hinged support fall in the range of 1.57 1.70, which are still within the limited criteria. Therefore, current results reveal that the presented door structures can meet the essential requirement in protection level, keeping the door at repairable and operable states after detonation.

To get insight into the dynamic behavior, the stress propagation scenarios developed with the time are further depicted in Fig. 12, in which the impact stresses rapidly propagate from centre of the surface plate into interior stiffener and then spread to the boundary of door structure along stiffener.

Moreover, in Table 4, comparisons of the peak stress generated in stiffener and cover plate imply the fact that the impact energy can be effectively absorbed by the inter-stiffeners and hence lessen the damage to the cover plate.

This again indicates that under the dynamic loading mode the stiffeners have sustained the majority of the explosive loadings transferred from cover plate after detonation, but showing a better effectiveness than under the case of static loading mode. Such an effect can further be rated in terms of the ratio of stiffener stress to plate stress (Table 4), which was showed to be enhanced with the increase of web thickness of stiffener.

It can be seen from Fig. 12 that highest stresses are locally generated at the transverse stiffener near the hinged sides of door. The observed peak stress in this region ranges between 908 and 1259MPa for different web thickness, which significantly exceed the dynamic yield strength (320MPa) and ultimate strength $(536 \mathrm{MPa})$ of the stiffener material, indicating the occurrence of the failure at these locations. The cover plates are subjected to higher stress at their tips and edges with maximum stress ranging from 339 to $410 \mathrm{MPa}$, which are marginally lower 
'Table 4. Comparisons of the maximum deflections and principal stresses predicted under static and dynamic loading modes, respectively. (Stiffener depth $\boldsymbol{H}=\mathbf{1 5 0} \mathbf{~ m m}$ )

\begin{tabular}{|c|c|c|c|c|c|c|c|c|}
\hline \multirow{3}{*}{$\begin{array}{c}\text { Web } \\
\text { thickness } \\
(\mathrm{mm})\end{array}$} & \multicolumn{4}{|c|}{ Static loading mode } & \multicolumn{4}{|c|}{ Dynamic loading mode } \\
\hline & \multirow{2}{*}{$\begin{array}{l}\text { Maximum } \\
\text { defection } \\
(\mathrm{mm})\end{array}$} & \multirow{2}{*}{$\begin{array}{c}\text { Rotational } \\
\text { deformation } \\
\text { (degree) }\end{array}$} & \multicolumn{2}{|c|}{$\begin{array}{c}\text { Maximum principal stress } \\
(\mathrm{MPa})\end{array}$} & \multirow{2}{*}{$\begin{array}{c}\text { Maximum } \\
\text { defection } \\
(\mathrm{mm})\end{array}$} & \multirow{2}{*}{$\begin{array}{c}\text { Rotational } \\
\text { deformation } \\
\text { (degree) }\end{array}$} & \multicolumn{2}{|c|}{ Maximum principal stress (MPa) } \\
\hline & & & Plate edges & Stiffener edges & & & Plate edges & Stiffener edges \\
\hline 5.5 & 32.46 & 1.45 & 482 & 968 & 37.94 & 1.70 & 410 & 1259 \\
\hline 6.5 & 30.59 & 1.37 & 473 & 842 & 36.65 & 1.64 & 396 & 1119 \\
\hline 7.5 & 29.17 & 1.30 & 464 & 742 & 35.71 & 1.60 & 373 & 1003 \\
\hline 8.5 & 28.0 & 1.25 & 457 & 664 & 35.00 & 1.57 & 339 & 908 \\
\hline
\end{tabular}

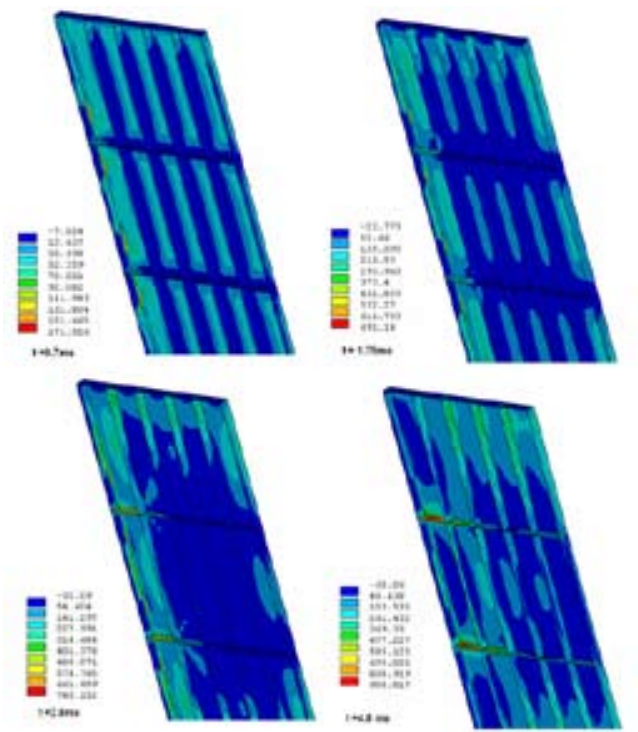

Fig. 12. Finite element predictions of transient response of the door structure subjected to explosive loading, showing the variations of the principal stress distribution at different time step. Stiffener depth=150 and web thickness $=8.5 \mathrm{~mm}$. (stress unit: MPa)

than the dynamic yield strength (289MPa) and ultimate strength (516MPa) of the plate, implying a local yielding of the cover plate. Herein, the dynamic yielding strength, rather than the static yield strength, was adopted to evaluate the possibility to damage of door structure subjected to the dynamic explosive loading of high rate.

Reviewing the stress generated in the presented door structures under explosive loads, it is known that the hinged edges of the transverse stiffeners could be a dangerous site initiating the localized failure. However the immediately overall failure of the door structure would not appear to occur since the cover plate remained in post yielding behavior at regions of above yielding stress or remained elastic at regions of lower stresses. The contribution of the stiffener to the dynamic response could thus be identified from current results; meanwhile, the impact stress of the door structure can be reduced essentially by the stiffener configuration, apart from the stiffener size. As shown in Fig. 13, the addition of a stiffener transversely located at the mid-line of the plate results in a reduction of the defection and stress of

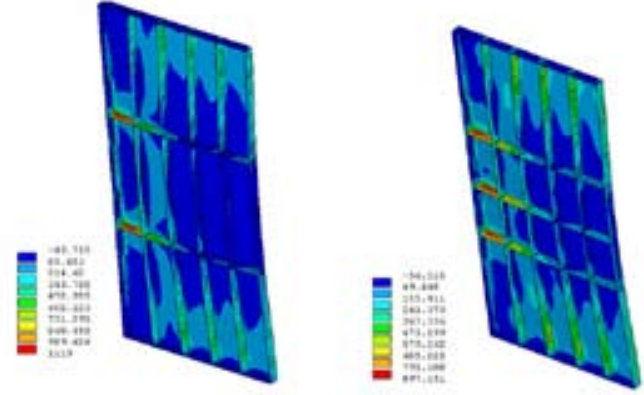

Fig. 13. Effect of stiffener configuration on the dynamic response of blast door (stiffener depth=150, web thickness $=6.5 \mathrm{~mm}$ ), showing a different stress state. The right one with three transverse stiffeners has a lower principal stress of $897 \mathrm{MPa}$ and a maximum deflection of $11.0 \mathrm{~mm}$. The left one with two transverse stiffeners has a higher stress of 1119MPa and maximum deflection of $36.7 \mathrm{~mm}$.

structure. It is found that the peak stress of stiffener is greatly reduced to $897 \mathrm{MPa}$, approximately a reduction of $20 \%$ of original design; and the maximum deflection is decreased by $70 \%$. This clearly demonstrates that the blast resistance of the blast door was dominated by the stiffener size and their configurations in the structure. As a final validation of static experiments, a stiffener of the depth of $150 \mathrm{~mm}$ and web thickness of $6.5 \mathrm{~mm}$ was suggested for door structure.

\section{STATIC EXPERIMENTS AND NUMERICAL VALIDATION}

To validate the shock resistance of the blast structure designed under the specified explosive loading, a static stiffness experiment was performed on a full sale prototype fabricated according to the suggested dimensions. In conventional practice, the experiment was carried out following the static test criteria suggested in UFGS-08390 for blast resistance door structure and the dynamic explosive loading was converted into equivalent static loading applied on the door specimen by utilizing a six-point jack loading method. Meanwhile according to the test criteria given in TM5-1300, a static pressure used for test should be at least two times of the blast overpressure. To produce the corresponding overpressure of $0.6 \mathrm{MPa}$, the forces at 


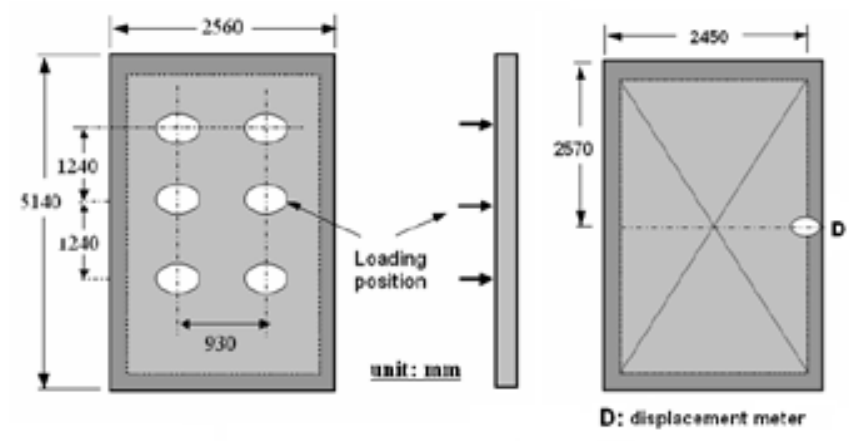

Fig. 14. Schematic of the prototype static test configured by six points loading method. The loading jacks are positioned at front plate and the displacement meter is mounted on the rear plate. (unit: mm)

Table 5. Comparisons of the maximum displacements obtained from

\begin{tabular}{|c|c|c|c|}
\hline \multirow{2}{*}{$\begin{array}{l}\text { Loading } \\
\text { direction }\end{array}$} & \multirow{2}{*}{$\begin{array}{l}\text { Equivalent blast } \\
\text { load applied by } \\
\text { jacks }(\mathrm{Kg})\end{array}$} & \multicolumn{2}{|c|}{ Maximum displacement (mm) } \\
\hline & & $\begin{array}{c}\text { Prototype static } \\
\text { experiment }\end{array}$ & $\begin{array}{c}\text { Finite element } \\
\text { computation }\end{array}$ \\
\hline $\begin{array}{l}\text { Positive } \\
\text { pressure }\end{array}$ & 763 & 0.48 & 0.4909 \\
\hline $\begin{array}{l}\text { Negative } \\
\text { pressure }\end{array}$ & 677 & 0.54 & 0.5245 \\
\hline
\end{tabular}

each point should be applied up to $240 \mathrm{Kg}$ by using a jack with bearing area of $196350 \mathrm{~mm}^{2}$, which provides the pressure $(1.22$ $\mathrm{MPa}$ ) to be higher than the test specification. The test configuration was demonstrated in Fig. 14. For positive blast pressure test, a forward load was applied on the front cover plate to seat the door into the metal doorframe. The load was held five minutes to record the deformation using a displacement meter mounted on the outer face of cover plate. For blast pressure of negative phase, the meter and loading jacks were positioned on the rear plate. Such a loading unseated door from the door frame, modeling the rebounding effect on the door structure.

Table 5 shows the results of the experiment, in which the average load afforded by each jack is $763 \mathrm{Kg}$ for positive pressure test and $677 \mathrm{Kg}$ for negative pressure test, respectively. The maximum deflection of the door structure measured under forward pressure is $0.48 \mathrm{~mm}$, less than the value $(0.54 \mathrm{~mm})$ measured under negative pressure. Such a difference can be ascribed to the fact that the metal doorframe constrained the top and bottom edges of the inside cover plate and hence prohibited the further deformation of door structure under positive loading.

Moreover, it is noted that the loads applied by the jack during the test were higher than $600 \mathrm{Kg}$. Such a load level substantially yields a highly localized pressure of $2.5 \mathrm{MPa}$ acting on the door plate, a more rigorously static explosive blast loads than that suggested in TM5-1300. For validating the experiment, the loads and boundary conditions replicating from experiment was applied on the previously used FE models for numerical simulation. The numerically predicted results are also listed in Table 5 for comparison. It is obvious that the numerical results agree well with the experimental ones. This clearly shows that the structure stiffness of the prototype proposed in this study has satisfied the design requirement in resistance to blast loadings.

\section{CONCLUSION}

In this study, we focus on investigating the blast resistance of a stiffened door structure with inter-stiffeners through the technology of computer aided analysis, instead of the analytical method presented in conventional design guideline. To this purpose, a simplified mathematical model was employed to establish the blast characteristic. The use of this model can prevent the inconveniency in enquiring the blast data from TM5-1300/NAVFAC P-397 menu. A series of analysis were then performed to investigate the effect of inter-stiffener size on the stiffness and stress state of door structure under static and dynamic explosive loading conditions, respectively. Current results clearly revealed that increasing the depth and web thickness of the stiffener can reduce the stress level and deflection of the door remarkably. According to the predicted results, an appropriate stiffener dimension was suggested to fabricate a full scale prototype of door structure for subsequent static stiffness test. The experimental results were further verified by finite element simulation on a physical FE model with the corresponding loading and boundary condition. Regardless of the positive or negative loading mode, the numerical predicted results compared well with the experimental results. Summarizing the above results, we could draw the conclusion that the analysis model established in this study can be used to evaluate the performance of a stiffened door structure with different blast resistance, material properties or stiffener configuration.

\section{ACKNOWLEDGEMENTS}

The authors are grateful for the financial support provided by the National Science Council of Taiwan under the grant of NSC92-2622-E-253-005-CC3. The assistances from Wei-Jie Engineering Co., Ltd and Song-Yang Machinery Industrial Co., Ltd, respectively, for preparation of the test specimen and implementation of experiments, are also greatly appreciated.

\section{REFERENCES}

1. Brode, H. L., "Numerical solution of spherical blast waves", Journal of Applied Physics, American Institute of Physics, New York, 1955.

2. Department of the Army, "Structures to resist the effects of accidental explosive," TM5-1300, Washington, D.C. (1990).

3. Department of the Navy, "Structures to resist the effects of accidental explosive," NAVFAC P-397, Design Manual, Alexandria, VA. (1991).

4. Hopkinson, B., British Ordnance Board Minutes, 13565, (1915).

5. Hsin, Y. L., and Hong, H., "Reliability analysis of direct shear and flexural failure modes of RC slabs under explosive loading," Engineering Structure, Vol. 24, pp. 189-198 (2002).

6. Kinney, G. F., and Graham, K. J., Explosive shocks in air, 2nd ed. Springer, Berlin Heidelberg, New York (1985).

7. Langdon, G. S., Yueh, K., Chung, S., Nurick, G. N., "Experimental and numerical studies on the response of quardrangular stiffened plates. Part II: Localised blast loading," Internation Journal of Impact Engngeering, 
Vol. 31, No. 1, pp. 85-111 (2005).

8. Louca, L. A., Pan, Y. G., and Harding, J. E., "Response of stiffened and unstiffened plates subjected to blast loading," Engineering Structure, Vol. 20, No. 12, pp. 1076-1086 (1998).

9. Malvar, L. J., and Crawford, J. E., "Dynamic increase factors for steel reinforcing bars," Twenty-Eighth DDESB Seminar, Orlando, FL, August (1998).

10. Miller, C. A., "The design of concrete structures to resist explosions and weapon effects," Proceeding of 1st International conference for hazard protection, Edinburgh (1987).

11. Newmark, N. M. and Hansen, R. J., "Design of blast resistant structures," Shock and Vibration Handbook, Vol. 3, Eds. Harris and Crede. McGraw-Hill, New York, USA. 1961.

12. Nurick, G. N., Olson, M. D., Fagnan, J. R., "Deformation and tearing of blast loaded stiffened square plates," Internation Journal of Impact
Engngeering, Vol. 16, No. 1, pp. 273-291 (1995).

13. Nurick, G. N., and Shave, G. C., "The deformation and tearing of thin square plates subjected to impulsive loads-an experimental study," Internation Journal of Impact Engngeering., Vol. 18, No. 1, pp. 99-116 (1996).

14. Rudrapatna, N. S, Vaziri, R., and Olson, M. D., "Deformation and failure of blast-loaded stiffened plate," Internation Journal of Impact Engngeering, Vol. 24, No. 5, pp. 457-474 (2000).

15. Swisdak, M. M., and Ward, J. M., "The DDESB Blast Effects Computer - Version 4.0," Minutes of the $29^{\text {th }}$ DoD Explosives Safety Seminar, July (2000).

16. Zhu, L., "Transient deformation modes of square plates subjected to explosive loadings," International Journal of Solid Structures, Vol. 33, No. 3, pp. 301-314 (1996). 
